Chie Suzuki • Motoko Unoki • Yusuke Nakamura

\title{
Identification and allelic frequencies of novel single-nucleotide polymorphisms in the DUSP1 and BTG1 genes
}

Received: December 20, 2000 / Accepted: December 22, 2000

\begin{abstract}
Defects in the activity of the PTEN gene, a tumor suppressor, are implicated in many types of cancer in humans. However, not all mediators of PTEN signaling pathways have been clarified, and, during efforts to identify such molecules, we previously induced expression of the DUSP1 and BTG1 genes by introducing exogenous PTEN into endometrial cancer cell lines. In the course of analyzing these two genes for mutations in ovarian carcinomas, we identified a novel single-nucleotide polymorphism (SNP) in the DUSP1 gene, and three novel SNPs in the BTG1 gene, and we have established their allelic frequencies in a Japanese population sample. These polymorphic sites will be useful for detecting losses of heterozygosity $(\mathrm{LOH})$ in tumors and for examining latent associations between specific alleles and disease susceptibility.
\end{abstract}

Key words Single-nucleotide polymorphism - DUSP1 . $B T G 1 \cdot P T E N \cdot$ Tumor suppressor

\section{Introduction}

The PTEN tumor suppressor gene encodes a multifunctional phosphatase that plays an important role in inhibiting the phosphatidylinositol-3-kinase pathway, and in downstream functions that include the activation of Akt/protein kinase B, cell survival, and cell proliferation (Maehama and Dixon 1998; Stambolic et al. 1998). Enforced expression of $P T E N$ in various cancer cell lines decreases cell proliferation through arrest of the cell cycle, accompanied, in some instances, by the induction of apoptosis (Furnari et al. 1998; Minaguchi et al. 1999). We used cDNA microarrays containing 4009 cDNAs to examine changes in gene expression profiles when exogenous $P T E N$ was introduced into PTEN-

C. Suzuki · M. Unoki · Y. Nakamura $(\bowtie)$

Laboratory of Molecular Medicine, Human Genome Center,

Institute of Medical Science, University of Tokyo, 4-6-1

Shirokanedai, Minato-ku, Tokyo 108-8639, Japan

Tel. +81-3-5449-5372; Fax +81-3-5449-5433

e-mail: yusuke@ims.u-tokyo.ac.jp defective endometrial cancer cell lines, and we found that exogenous PTEN induced expression of the DUSP1 and $B T G 1$ genes (unpublished data).

DUSP1/MKP1/CL100/PTPN10, a dual-specificity phosphatase for tyrosine and threonine, specifically inactivates mitogen-activated protein kinase (MAPK) and suppresses its activation by ras (Alessi et al. 1993). BTG1 encodes a member of the anti-proliferative Tob/BTG1 family of molecules; transfection experiments have indicated that BTG1 negatively regulates cell proliferation (Rouault et al. 1992).

Therefore, in view of our results from the microarray experiments, we considered these two genes to be candidates for mediating PTEN signaling pathways. We screened both genes for mutations in ovarian cancers and found none, but we did identify four single-nucleotide polymorphisms (SNPs) in non-coding regions. Here we describe these novel SNPs and report their allelic frequencies in a Japanese population sample.

\section{Subjects and methods}

DNA samples. Materials used in this study were obtained, with informed consent, from 132 Japanese individuals. Genomic DNAs were extracted according to standard protocols.

Screening of SNPs. Amplification of genomic DNA fragments by polymerase chain reactions (PCRs) and DNA sequencing of the amplified fragments were performed as described previously (Lin et al. 2000).

SNP typing. SNPs were genotyped by allele-specific oligonucleotide (ASO) hybridization as described previously (Unoki et al. 2000). Allele-specific probes $\left({ }^{32} \mathrm{P}\right.$-labeled 13to 17 -mers) of $5^{\prime}$-TACGCCCTCGGGG-3' or 5'-TACGCC GTCGGGG-3' for C(IVS +8$) \mathrm{G}$ of DUSP1, and $5^{\prime}$ GGGTGGCTGCTCC-3' or 5'-GGGTGGTTGCTCC-3' for $\mathrm{C}(-67 \mathrm{~T})$ of $B T G 1$, were hybridized at $37^{\circ} \mathrm{C}$ to the polymerase chain reaction $(\mathrm{PCR})$ products on the membranes 
Table 1. Primer sequences for amplifying the coding regions and splice sites of the DUSP1 and the BTG1 genes

\begin{tabular}{|c|c|c|c|}
\hline Gene & $\begin{array}{l}\text { Name of } \\
\text { primer }\end{array}$ & Nucleotide sequences & $\begin{array}{l}\text { Product } \\
\text { size (bp) }\end{array}$ \\
\hline \multirow[t]{14}{*}{ DUSP1 } & DUSP1-F1 & 5'-CGTCACGTGATCACCATTCA-3' & \multirow[t]{2}{*}{499} \\
\hline & DUSP1-R1 & 5'-TGAAGCGCACGTTGACAGAG-3' & \\
\hline & DUSP1-F2 & 5'-CCAAAAGCGGCTTTTGGTTC-3' & \multirow[t]{2}{*}{695} \\
\hline & DUSP1-R2 & 5'-AGGGCTGGAAGTTTACATCG-3' & \\
\hline & DUSP1-F3 & 5'-CGATGTAAACTTCCAGCCCT-3' & \multirow[t]{2}{*}{420} \\
\hline & DUSP1-R3 & 5'-AGCCTACAATTGGAGACTCG-3' & \\
\hline & DUSP1-F4 & 5'-CСТCCAGCAACAGAACTGAG-3' & \multirow[t]{2}{*}{492} \\
\hline & DUSP1-R4 & 5'-ACAGGAATGTTGCCCACACC-3' & \\
\hline & DUSP1-F5 & 5'-CATGTGATGGCATGTGGTGA-3' & \multirow[t]{2}{*}{609} \\
\hline & DUSP1-R5 & 5'-AATAAGGACCAGCCCTCTCG-3' & \\
\hline & DUSP1-F6 & 5'-CACCACCACCGTGTTCAACT-3' & \multirow[t]{2}{*}{607} \\
\hline & DUSP1-R6 & 5'-CAGTGCTGAAAACAAACCTGC-3' & \\
\hline & DUSP1-F7 & 5'-CCCGACGACACATATACATAT-3' & \multirow[t]{2}{*}{535} \\
\hline & DUSP1-R7 & 5'-AGAGTTCAGCTGTAGCGTCC-3' & \\
\hline \multirow[t]{4}{*}{ BTG1 } & BTG1-F1 & 5'-GGTGCGATATTCGGATTGGC-3' & \multirow[t]{2}{*}{616} \\
\hline & BTG1-R1 & 5'-GACTCTGACCCAGGGATGTG-3' & \\
\hline & BTG1-F2 & 5'-AACAACGGATGCAATCCTGG-3' & \multirow[t]{2}{*}{932} \\
\hline & BTG1-R2 & 5'-СТTTCСТАTTAAAAGCTGCCG-3' & \\
\hline
\end{tabular}

Table 2. Allelic frequencies of SNPs of the DUSP1 and the BTG1 genes in a Japanese population

\begin{tabular}{lllll}
\hline Gene & Region & SNPs and their flanking sequence & \multicolumn{2}{c}{ Allelic frequencies $^{\mathrm{a}}$} \\
\hline DUSP1 & Intron1 & AAGGTACGCC (C/G) TCGGGGAAGC & $\mathrm{C}$ & $\mathrm{G}$ \\
& IVS1 + 8 & & 0.68 & 0.32 \\
BTG1 & 5'UTR (exon1) & AGCTATTGAG (A/G) TCTTCGAATG & A & G \\
& (-278) & & 0.64 & 0.36 \\
& 5'UTR (exon1) & CCCGGGGTGG (C/T) TGCTCCGCCG & $\mathrm{C}$ & $\mathrm{T}$ \\
& (-67) & & 0.65 & 0.35 \\
& 5'UTR (exon1) & GCCGAGCCCC (G/A) GCCGCCCCGG & G & A \\
& $(-33)$ & & 0.67 & 0.33 \\
\hline
\end{tabular}

SNP, Single-nucleotide polymorphism; UTR, untranslated region

${ }^{\text {a }}$ Estimated from the genotyping of 264 chromosomes

and washed in $6 \times$ standard saline citrate $(\mathrm{SSC})$ at $42^{\circ} \mathrm{C}$ (DUSP1) or at $46^{\circ} \mathrm{C}$ (BTG1) according to standard protocols. Genomic DNAs (50-ng each) were amplified by PCR, and each PCR product was digested with $B g l \mathrm{II}$ for A(-278)G of BTG1 or with Eco52I for G(-33)A of BTG1, according to the manufacturer's protocol (TaKaRa).

\section{Results and discussion}

By screening all coding exons and their neighboring introns in the DUSP1 and BTG1 genes, using the PCR primers listed in Table 1, we detected four novel SNPs, one in the DUSP1 gene and three in the BTG1 gene. To estimate the allelic frequency of each SNP in the Japanese population, we genotyped a panel of 132 subjects, with the results shown in Table 2.

The SNP in the DUSP1 gene is located in intron 1 and all three SNPs in the BTG1 gene are located in the $5^{\prime}$ untranslated region. Because none of these polymorphic sites is within a coding region, none is likely to influence the function of the gene product, although we cannot exclude the possibility that certain alleles might alter the efficiency of translation or transcription. Nevertheless, these polymorphisms should be useful for detecting losses of heterozygosity (LOH) in tumors and for examining potential associations between specific alleles and disease susceptibility.

\section{References}

Alessi DR, Smythe C, Keyse SM (1993) The human CL100 gene encodes a tyr/thr-protein phosphatase which potently and specifically inactivates MAP kinase and suppresses its activation by oncogenic ras in Xenopus oocyte extracts. Oncogene 8:2015-2020

Furnari FB, Huang HJ, Cavenee WK (1998) The phosphoinositol phosphatase activity of $P T E N$ mediates a serum-sensitive G1 growth arrest in glioma cells. Cancer Res 58:5002-5008

Lin YM, Kato T, Satoh S, Nakamura Y, Furukawa Y (2000) Identification of novel polymorphisms in the $A X I N 1$ and $C D X-2$ genes. J Hum Genet 45:254-256

Maehama T, Dixon JE (1998) The tumor suppressor, PTEN/MMAC1, dephosphorylates the lipid second messenger, phosphatidylinositol 3,4,5-trisphosphate. J Biol Chem 273:13375-13378

Minaguchi T, Mori T, Kanamori Y, Matsushima M, Yoshikawa H, Taketani Y, Nakamura Y (1999) Growth suppression of human ovarian cancer cells by adenovirus-mediated transfer of the PTEN gene. Cancer Res 54:6063-6067 
Rouault JP, Rimokh R, Tessa C, Paranhos G, Ffrench M, Duret L, Garoccio M, Germain D, Samarut J, Magaud JP (1992) BTG1, a member of a new family of antiproliferative genes. EMBO J $11: 1663-1670$

Stambolic V, Suzuki A, de la Pompa JL, Brothers GM, Mirtsos C, Sasaki T, Ruland J, Penninger JM, Siderovski DP, Mak TW (1998) Negative regulation of $\mathrm{PKB} / \mathrm{Akt}$-dependent cell survival by the tumor suppressor PTEN. Cell 95:29-39
Unoki M, Furuta S, Onouchi Y, Watanabe O, Doi S, Fujiwara H, Miyatake A, Fujita K, Tamari M, Nakamura Y (2000) Association studies of 33 single nucleotide polymorphisms (SNPs) in 29 candidate genes for bronchial asthma: positive association of a T924C polymorphism in the thromboxane A2 receptor gene. Hum Genet 106:440-446 